University of Nebraska - Lincoln

DigitalCommons@University of Nebraska - Lincoln

$10-23-2003$

\title{
Electrochemical preparation of chitosan/hydroxyapatite composite coatings on titanium substrates
}

Jody G. Redepenning

University of Nebraska-Lincoln, jredepenning1@unl.edu

Guhanand Venkataraman

University of Nebraska - Lincoln

Jun Chen

University of Nebraska - Lincoln

Nathan Stafford

University of Nebraska - Lincoln, nstaffor@unlserve.unl.edu

Follow this and additional works at: https://digitalcommons.unl.edu/chemistryredepenning

Part of the Chemistry Commons

Redepenning, Jody G.; Venkataraman, Guhanand; Chen, Jun; and Stafford, Nathan, "Electrochemical preparation of chitosan/hydroxyapatite composite coatings on titanium substrates" (2003). Jody Redepenning Publications. 1.

https://digitalcommons.unl.edu/chemistryredepenning/1

This Article is brought to you for free and open access by the Published Research - Department of Chemistry at DigitalCommons@University of Nebraska - Lincoln. It has been accepted for inclusion in Jody Redepenning Publications by an authorized administrator of DigitalCommons@University of Nebraska - Lincoln. 


\title{
Electrochemical preparation of chitosan/hydroxyapatite composite coatings on titanium substrates
}

\author{
Jody Redepenning,* Guhanand Venkataraman, Jun Chen, and Nathan Stafford \\ Department of Chemistry, University of Nebraska-Lincoln \\ *Corresponding author: Jody Redepenning, Department of Chemistry, University of Nebraska-Lincoln, Hamilton Hall, Lincoln, \\ Nebraska 68588-0304. E-mail: jredepen@unlserve.unl.edu \\ Research funded by National Science Foundation Grant Number DMR-9972587 and Nebraska Center for Materials Research and \\ Analysis.
}

\begin{abstract}
Composite coatings containing brushite $\left(\mathrm{CaHPO}_{4} \cdot 2 \mathrm{H}_{2} \mathrm{O}\right)$ and chitosan were prepared by electrochemical deposition. The brushite/chitosan composites were converted to hydroxyapatite/chitosan composites in aqueous solutions of sodium hydroxide. The coatings ranged from 1 to $15 \%$ chitosan by weight. Qualitative assessment of the coatings showed adhe-
\end{abstract}

sion significantly improved over that observed for electrodeposited coatings of pure HA.

Keywords: electrodeposition, hydroxyapatite, brushite, chitosan, composite

Submitted November 2001; revised August 2002; accepted September 2002; published July 2003.

\section{INTRODUCTION}

Hydroxyapatite (HA) has been the focus of a significant research effort devoted to devising osteoconductive materials that improve the performance of metal implants, such as the femoral component of a total hip prosthesis. Clinical studies have shown that coating the femoral prosthesis with hydroxyapatite promotes an early osseous response that improves the bonding strength of the prosthesis to the femur.[1-3]

In 1990 we introduced a relatively simple, low-temperature electrochemical procedure for reproducibly depositing calcium phosphate materials on conducting surfaces.[4] This non-line-of-sight procedure can be used to coat irregularly shaped surfaces while maintaining control over deposit crystallinity. In a typical deposition, the $\mathrm{pH}$ near the surface of the device is raised by using the device as the cathode in aqueous electrolyte solutions containing calcium ions, dihydrogen phosphate, and monohydrogen phosphate.[5]

The resulting precipitate, usually brushite $\left(\mathrm{CaHPO}_{4}\right.$ - $\left.2 \mathrm{H}_{2} \mathrm{O}\right)$ or monetite $\left(\mathrm{CaHPO}_{4}\right)$, can be converted to hydroxyapatite by following procedures first developed by Tiselius in 1956.[6] In short, these procedures involve using strongly basic aqueous solutions to deprotonate,

Published in Journal of Biomedical Materials Research 66A (2003), 411-416. Copyright (C) 2003 Wiley Periodicals, Inc. Used by permission. expel phosphate ions, and rearrange the lattice to produce well crystallized hydroxyapatite with a macroscopic morphology similar to that of the original deposit.

Electrodeposited calcium phosphate coatings are the focus of a significant number of investigations.[7-15] A recent article that appeared in this journal is particularly noteworthy.[16]

The brittleness of hydroxyapatite and its adhesion to metal surfaces are possible limitations when shear forces or other loads are great. Although one of the advantages of electrochemical deposition is that the technique can be use to produce calcium phosphate coatings on porous and irregularly shaped surfaces where the shear forces and loads are not so great, any migration of particulate HA to articulating surfaces of an artificial hip could lead to reasonable concerns associated with excessive wear. Consequently, we have investigated a number of means by which electrodeposited calcium phosphate coatings can be stabilized.

We wanted a second generation of electrodeposited coatings with material properties more like living bone, a material that could be viewed as a complex composite with mechanical properties very different from crystalline hydroxyapatite. More specifically, we desired a composite material containing rigid inorganic regions separated by more flexible organic constituents. Our initial focus has been on preparing HA composites containing naturally occurring biopolymers with well established biocompatibility. Chitosan is one such polymer. 
Chitosan, which is shown in an idealized form below, is a simple polymer of glucosamine

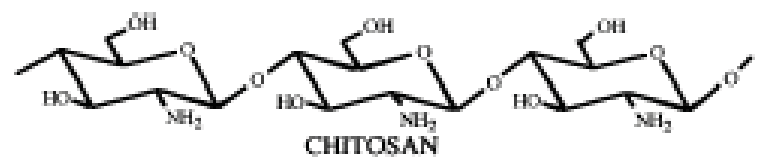

that is very similar to cellulose, a polymer of common sugars. Chitosan is a biodegradable and biocompatible polymer that has found widespread use in the cosmetics and food industries. Chitosan also has been widely studied for applications in medicine: it is known to be highly osteoconductive. [17-19] Studies have shown that chitosan is a hemostatic material [20] [21] and that it has a beneficial influence on wound healing [22] and on bone reformation. [23]

Chitosan exhibits structural similarities to glycosaminoglycans in the mineral-bound proteoglycans in bone, and since glycosaminoglycans are know to have stimulatory effects on matrix organization during tissue repair, it is believed that chitosan may have a similar role. [24] Several recent articles have focused on the biomedical uses and material properties of chitosan, chitosan derivatives, and chitosan-containing composites. [25-28]

The amine group of chitosan provides an opportunity to process chitosan in a straightforward manner. The amine group is a weak base. Consequently, chitosan can be protonated by weak acids, such as acetic acid, to give a water-soluble polymer that can be spun into fibers or cast into films. This solubility under acidic conditions allows us to deposit HA/chitosan composites on conducting substrates using an electrochemically induced $\mathrm{pH}$ jump. The synthetic sequence used to produce the desired composite coatings on metallic surfaces is a combination of electrochemical half reactions, acid-based reactions, and precipitation reactions.

First, water is reduced at the surface of the prosthesis to produce hydrogen gas and hydroxide ions, as shown in the following half reaction:

$$
2 \mathrm{H}_{2} \mathrm{O}+2 \mathrm{e}^{-}=\mathrm{H}_{2}+2 \mathrm{OH}^{-}
$$

The $\mathrm{pH}$ at the surface of the device is controlled by controlling the current or the potential at which the current is passed. Hydroxide ions generated at the surface react with dihydrogen phosphate according to the equilibrium shown below:

$$
\mathrm{OH}^{-}+\mathrm{H}_{2} \mathrm{PO}_{4}^{-} \rightleftharpoons \mathrm{H}_{2} \mathrm{O}+\mathrm{HPO}_{4}{ }^{2-}
$$

The following equilibrium, which is driven to the right hand side by the reactions listed above, results in the deposition of brushite on the surface of the device.

$$
\mathrm{Ca}^{2+}+\mathrm{HPO}_{4}{ }^{2-}+2 \mathrm{H}_{2} \mathrm{O} \rightleftharpoons \mathrm{CaHPO}_{4} \cdot 2 \mathrm{H}_{2} \mathrm{O}
$$

If chitosan also is present in acidic electrolyte solutions, such as those listed above, the reaction of protonated chitosan with hydroxide results in the co-deposition of neutralized chitosan with brushite, as is shown in the reaction below.

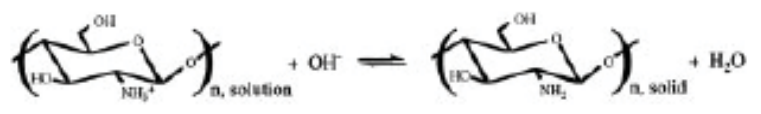

The resulting composite can be converted to a HA/ chitosan composite using a strong base.

\section{MATERIALS AND METHODS}

Electrodes typically were degreased by rinsing in acetone (99.5\%, EM Science), ethanol (99.5\%, Pharmco) and then drying in air before they were used for the electrochemical experiments. Anhydrous monobasic calcium phosphate (MCPA, Sigma), glacial acetic acid (99.7\%, Fisher), chitosan (min. 85\% deacetylated, Sigma), and sodium hydroxide pellets ( $98 \%$, Mallinckrodt) all were used as purchased.

A PAR Model 273 potentiostat/galvanostat was used to control the potential or current during deposition. A platinum basket was used as the anode. Potential measurements were made against a standard calomel electrode (Fisher). X-ray diffraction patterns were obtained using a Rigaku D/Max II B automated X-ray diffractometer, and SEM imaging and X-ray microanalysis were performed using a JEOL JSM 840A scanning electron microscope.

Stock solutions of aqueous calcium phosphates typically were prepared by adding $20 \mathrm{~g}$ of $\mathrm{Ca}\left(\mathrm{H}_{2} \mathrm{PO}_{4}\right)_{2}$ to 100 grams of distilled/deionized water. The solutions were stirred vigorously for $2 \mathrm{~h}$ and then filtered to remove excess brushite, which is the solid that ultimately equilibrates with this particular solution. [29] Stock solutions of dissolved chitosan were prepared by combining solid chitosan with an equal number of moles of acetic acid in water. The concentration of the chitosan stock solutions (based on the amino group) ranged from approximately 0.05 to 0.20 moles per kg of solvent. The electrolyte solutions used to deposit $\mathrm{HA}$ /chitosan composite coatings were prepared by combining aliquots of chitosan and calcium phosphate stock solutions.

\section{RESULTS, DISCUSSION, AND CONCLUSIONS}

In a typical deposition of pure brushite, a current density between $25 \mathrm{~mA} / \mathrm{cm}^{2}$ and $250 \mathrm{~mA} / \mathrm{cm}^{2}$ is passed for 1-10 min, and the resulting brushite coating is converted to hydroxyapatite by heating the sample for $24 \mathrm{~h}$ in $0.1 \mathrm{M}$ of $\mathrm{NaOH}(\mathrm{aq})$ at $95^{\circ}-100^{\circ} \mathrm{C}$. Alternatively, the conversion to hydroxyapatite can be accomplished by storing the coated implant for $72 \mathrm{~h}$ in $0.1 \mathrm{M}$ of $\mathrm{NaOH}(\mathrm{aq})$ at room temperature.

Figure 1 shows a low magnification SEM image of a typical HA coating on a beaded titanium substrate. This coating was obtained by depositing brushite at a constant 


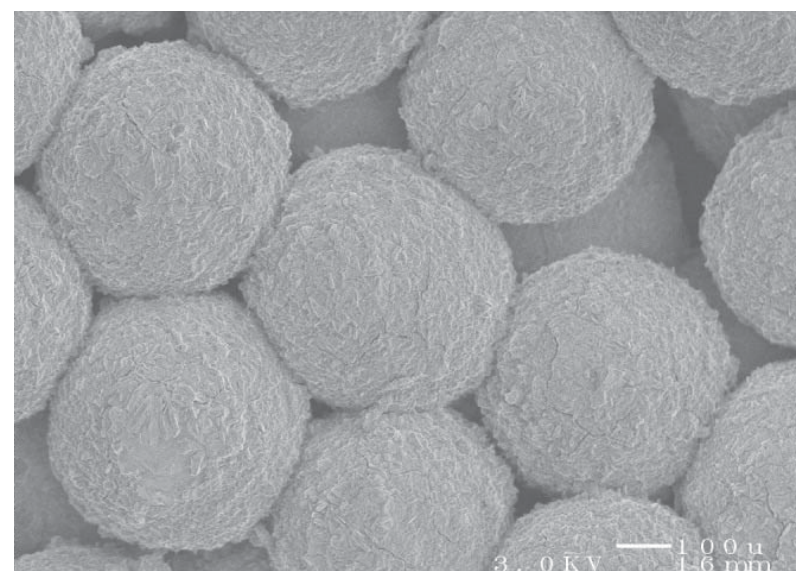

Figure 1. Scanning electron micrograph (SEM) of hydroxyapatite coating on titanium beads.

current of $25 \mathrm{~mA} / \mathrm{cm}^{2}$ for $5 \mathrm{~min}$. The coating was converted to hydroxyapatite by heating the sample for 24 $\mathrm{h}$ in $0.1 \mathrm{M}$ of $\mathrm{NaOH}(\mathrm{aq})$ at $95^{\circ} \mathrm{C}$ The relatively uniform coating on this irregularly shaped surface demonstrates one of the attractions of preparing calcium phosphate coatings in this manner, that is, that the process is not restricted to substrates for which a line-of-sight must be maintained.

The influence of the brushite-to-HA-conversion process on coating morphology is shown in Figure 2. Figure 2(A) shows a SEM image of a brushite coating prepared on a flat titanium substrate using a time-dependent controlled current. The current density during this deposition was ramped from $100 \mathrm{~mA} / \mathrm{cm}^{2}$ to $68.5 \mathrm{~mA} / \mathrm{cm}^{2}$ at $0.15 \mathrm{~mA} / \mathrm{s} / \mathrm{cm}^{2}$. Figure 2(B) shows the same location of the same coating after it was converted to HA by bathing the sample in $0.1 M$ of $\mathrm{NaOH}$ for 7 days at room temperature. It is clear that the macroscopic morphology of the coating is largely unchanged. The large angular features have the same macroscopic shape as the original brushite crystals, but no HA crystals are visible on this length scale. Upon closer examination, it appears that a dissolution/reprecipitation process has produced a more "leveled" surface containing a network of small cracks. We believe these cracks may be caused by the change in molar volume (based on calcium ions) that occurs upon conversion of $\mathrm{CaHPO}_{4} \cdot 2 \mathrm{H}_{2} \mathrm{O}$ to $\mathrm{Ca}_{5}\left(\mathrm{PO}_{4}\right)_{3} \mathrm{OH}$. Control of these cracks currently is under investigation.

Figure 3 shows the morphologic changes that occur upon converting brushite/chitosan composites to HA/ chitosan composites. The electrolyte solution in this case was prepared by mixing $48.5 \mathrm{~mL}$ of stock solution with $1.5 \mathrm{~mL}$ of a $4-w t \%$ solution of chitosan containing an equimolar amount of acetic acid. Again, the current density during the deposition was ramped from $100 \mathrm{~mA} /$ $\mathrm{cm} 2$ to $68.5 \mathrm{~mA} / \mathrm{cm}^{2}$ at $0.15 \mathrm{~mA} / \mathrm{s} / \mathrm{cm}^{2}$, and the conversion to $\mathrm{HA} /$ chitosan was achieved by bathing the sample in $0.1 M$ of $\mathrm{NaOH}$ for 7 days at room temperature.
In comparing Figures 2(A) and 3(A), a significant change in aspect ratio is observed for the brushite crystals, and it is clear that the composite coatings are much more ordered, possibly around nucleation sites for subsequent growth. Chitosan appears only as a thin film that coats the crystalline inorganic regions while partially filling the interstitial voids. Thus far we have only qualitative information concerning the physical properties of these composites. It is clear that the chitosan serves, in part, as a bioadhesive that strengthens the bonding between HA particles between HA and the surface. In fact, if the composite is deposited on a highly polished surface, using a sharp razor it can be remove as a flexible sheet.

It has been difficult for us to quantify the relative amounts of chitosan and hydroxyapatite in our composite coatings. These coatings present an unusual set of analysis problems that are not easily solved by any one analytical technique. Figure 4 shows powder XRD patterns for electrolytically deposited HA and HA/chitosan composites. All of the reflections expected for HA are observed in the pure HA and in the HA/chitosan composites, but only a broad peak at approximately $2 \theta=15^{\circ}$ is observed for the amorphous chitosan.
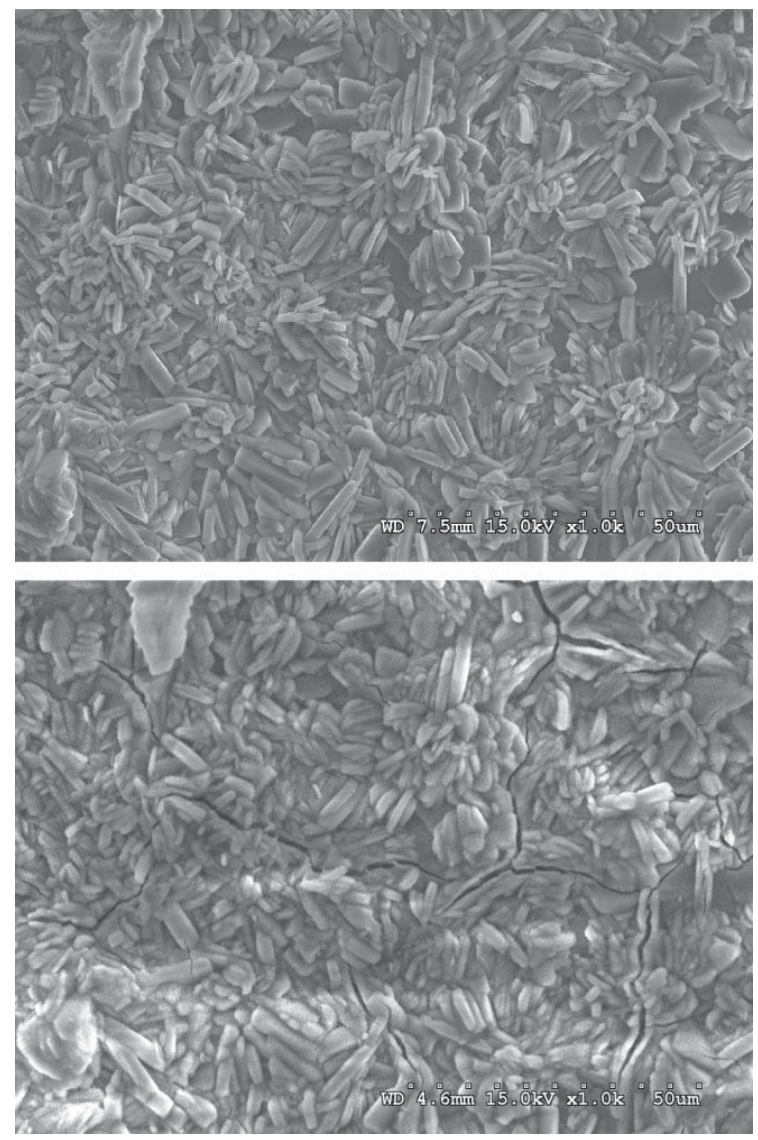

Figure 2. (A) SEM of electrodeposited brushite coating on flat titanium substrate; (B) SEM of same coating after conversion to HA. 

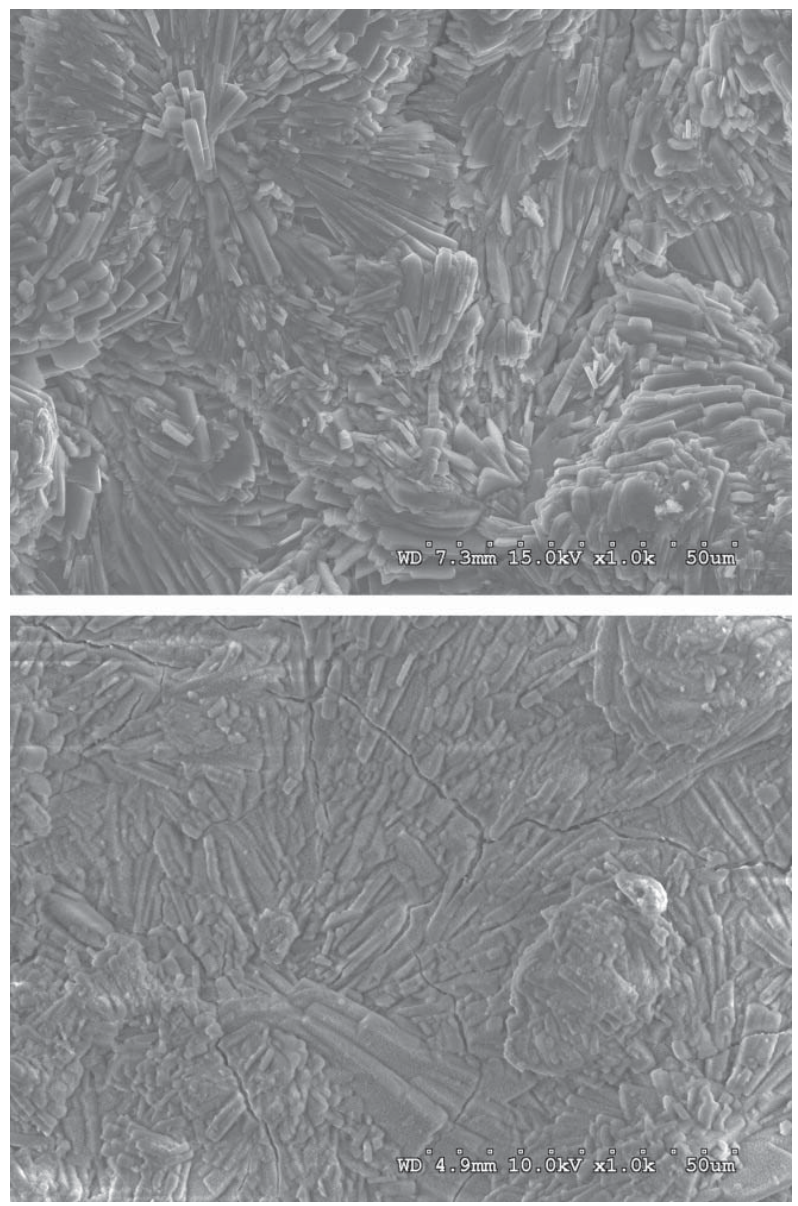

Figure 3. (A) SEM of electrodeposited brushite/chitosan composite on flat titanium substrate; (B) SEM of same coating after conversion to $\mathrm{HA}$ /chitosan.

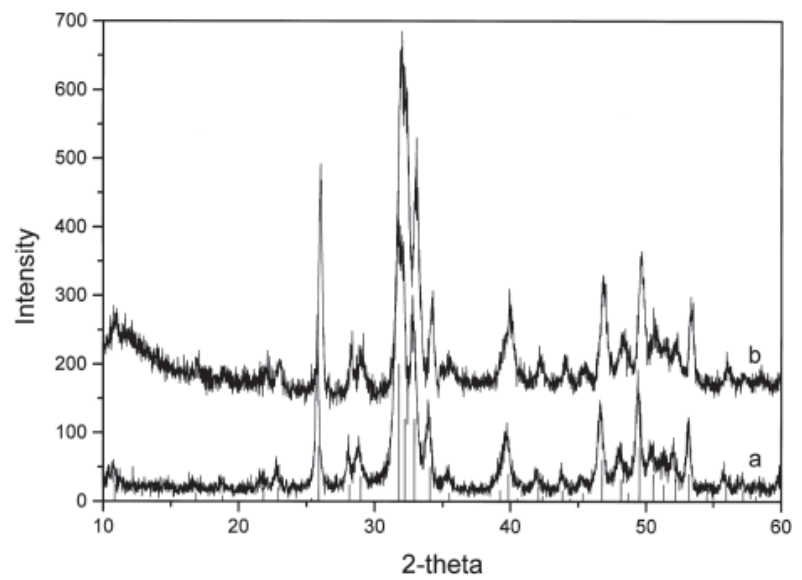

Figure 4. X-ray powder diffraction pattern of (a) electrodeposited HA coating, and (b) electrodeposited HA/chitosan composite coating.
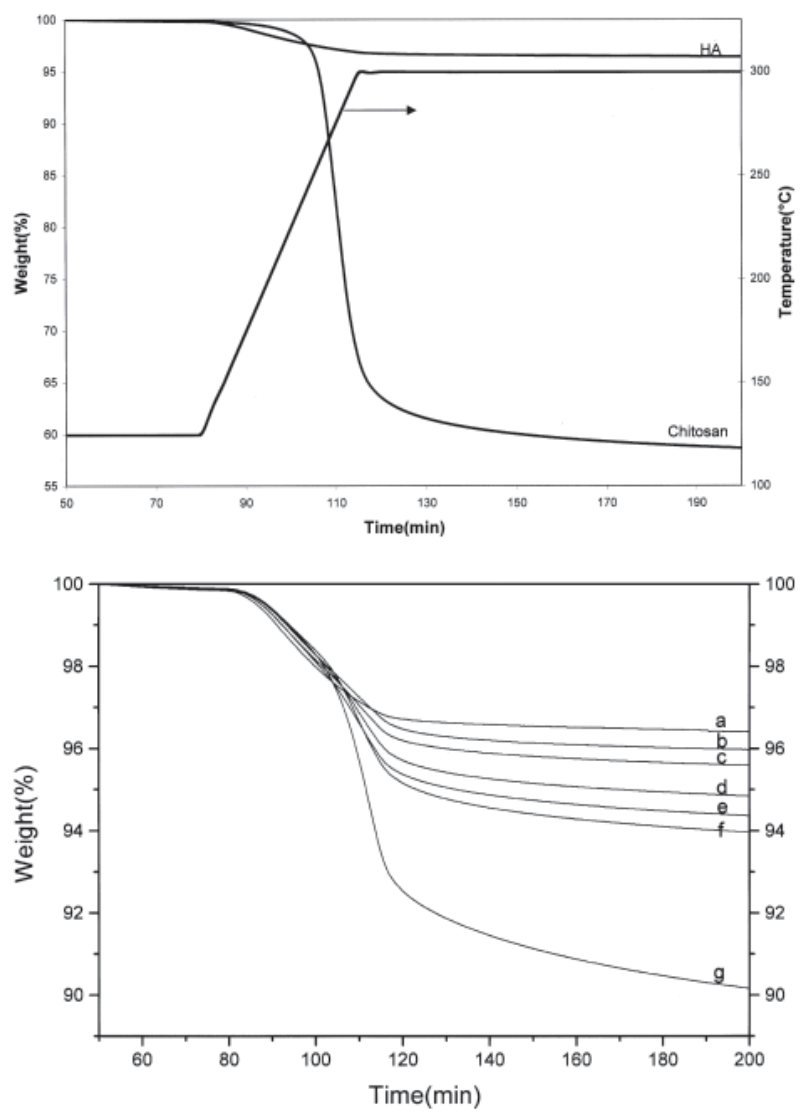

Figure 5. Thermogravimetric analysis of HA, chitosan, and HA/chitosan composites. (a) Thermal degradation of HA and chitosan monitored by percent of weight loss (left axis) as a function of time. Applied temperature (right axis) as a function of time also is shown. (b) Thermal degradation of HA/chitosan composites monitored by percent of weight loss as a function of time. Temperature program is the same as that shown in Figure 4 (a).

Thermogravimetric analysis (TGA) has proven to be the most expedient means of determining the overall composition of the composite coatings. It has been possible to measure the amount of chitosan in HA/chitosan composites by applying the temperature ramp shown in Figure 5(a). Following an 80-min dehydration step at $125^{\circ} \mathrm{C}$, we ramped the temperature from $125^{\circ}$ to $300^{\circ} \mathrm{C}$ at $5^{\circ} \mathrm{C}$ per min. Figure 5(a) also shows the thermogravimetric response of HA and chitosan. Chitosan undergoes a decomposition at approximately $200^{\circ} \mathrm{C}$ and loses about $40 \%$ of its mass. Under the same temperature program, HA undergoes a $3.6 \%$ mass change, which we attribute to the loss of strongly adsorbed water. Given these limits, it is possible to calculate the weight percent of HA and chitosan in HA/chitosan composites that undergo mass changes such as those shown in Figure $5(\mathrm{~b})$. The solution compositions, wt $\%$ of chitosan and wt $\%$ of HA for coatings shown in Figure 5 are tabulated in Table I. 
TABLE I

\begin{tabular}{|c|c|c|c|c|c|}
\hline & \multicolumn{3}{|c|}{ Solution Conditions } & \multirow[b]{2}{*}{$\begin{array}{c}\text { Weight } \\
\text { Loss } \\
(\%)\end{array}$} & \multirow[b]{2}{*}{$\begin{array}{l}\text { Weight } \% \text { of } \\
\text { Chitosan in } \\
\text { Composite }\end{array}$} \\
\hline & $\begin{array}{l}\text { Molality of } \\
\text { Chitosan } \\
(\mathrm{mol} / \mathrm{kg})\end{array}$ & $\begin{array}{l}\text { Molality of } \\
\mathrm{Ca}^{2+} \\
(\mathrm{mol} / \mathrm{kg})\end{array}$ & $\begin{array}{c}\text { Molality of } \\
\text { phosphates } \\
(\mathrm{mol} / \mathrm{kg})\end{array}$ & & \\
\hline $\mathrm{a}(\mathrm{HA})$ & 0 & 0.60 & 1.46 & 3.59 & 0 \\
\hline $\mathrm{b}$ & 0.0079 & 0.47 & 1.13 & 4.03 & 1.2 \\
\hline$c$ & 0.018 & 0.47 & 1.14 & 4.40 & 2.2 \\
\hline $\mathrm{d}$ & 0.035 & 0.47 & 1.14 & 5.16 & 4.2 \\
\hline e & 0.034 & 0.36 & 0.87 & 5.63 & 5.4 \\
\hline f & 0.047 & 0.47 & 1.14 & 6.03 & 6.5 \\
\hline $\mathrm{g}$ & 0.033 & 0.18 & 0.43 & 9.83 & 16 \\
\hline Chitosan & - & - & - & 41.4 & 100 \\
\hline
\end{tabular}

As expected, the data in Table I show that the ratio of the chitosan concentration in solution to that of the calcium phosphate in solution is an important determinant of the eventual relative compositions of chitosan and HA in the composite coatings. The absolute concentrations also play an important role in determining the composition and quality of the coatings. For concentrations of dissolved chitosan greater than approximately $0.05 \mathrm{~m}$, it has been our experience that the solutions become so viscous that efficient effervescence of hydrogen becomes difficult. Irregularly blistered chitosan has resulted. Our future work will include a more detailed examination of the extent to which the HA/chitosan composition can be varied and the extent to which this technique can be extended to include HA composites with other biopolymers.

\section{Acknowledgements}

It is a pleasure to acknowledge discussions with Dennis Chakkalakal.

\section{References}

1. Coventry MB. Lessons learned in 30 years of total hip arthroplasty. Clin Orthop 1992; 274:22-29.

2. Goldring SR, Clark CR, Wright TM. The problem in total joint arthroplasty: Aseptic loosening [editorial]. J Bone Joint Surg Am 1993; 75: 799-801.

3. Jasty M. Clinical reviews: Particulate debris and failure of total hip replacements. J Appl Biomater 1993; 4: 273-276.

4. Redepenning J, McIsaac JP. Electrocrystallization of brushite coatings on prosthetic alloys. Chem Mater 1990; 2: 625-627.

5. Redepenning J, Schlessinger T, Burnham S, Lippiello L, Miyano J. Characterization of electrolytically prepared brushite and hydroxyapatite coatings on orthopedic alloys. J Biomed Mater Res 1996; 30: 287-294.
6. Tiselius A, Hjerten S, Levin O. Protein chromatography on calcium phosphate columns. Arch Biochem Biophys 1956; 65: 132-155.

7. Chakkalakal DA, Redepenning J, Garvin KL, Quigley HJ, Novak JR, Fritz ED, Mollner TJ, Puls DL, McQuire MH. Adjuvant treatment with osteoconductive agents in a canine model of hip reconstruction. Eur J Exp Musculoskel Res 1995; 4: 176-187.

8. Royer P, Rey C. Calcium phosphate coatings for orthopedic prosthesis. Surf Coat Technol 1991; 45: 171177.

9. Shirkhanzadeh M. Bioactive calcium phosphate coatings by electrodeposition. J Mater Sci Lett 1991; 10: 1415-1417.

10. Zhang JM, Lin CJ, Feng ZD, Tian ZW. Hydroxyapatite/metal composite coatings prepared by multi-step electrodeposition method. J Mater Sci Lett 1998; 17: 1077-1079.

11. Chen JS, Juang HY, Mon MH. Calcium phosphate coating on titanium substrate by a modified electrocrystallization process. J Mater Sci: Mater Med 1998; 9: 297-300.

12. Kumar M, Xie J, Chittur K, Riley C. Transformation of modified brushite to hydroxyapatite in aqueous solution: Effects of potassium substitution. Biomaterials 1999; 20: 1389-1399.

13. Monma H, Nemoto O, Takahashi S, Kobayashi H. Electrolytic formation and morphology of biomimetic apatite coatings. J Electroceram 1999; 4: 135-140.

14. Manso M, Jimenez C, Morant C, Herrero P, Martinez-Duart JM. Electrodeposition of hydroxyapatite coatings in basic conditions. Biomaterials 2000; 21: 1755-1761.

15. Da Silva MHP, Lima JHC, Soares GA, Elias CN, deAndrade MC, Best SM, Gibson IR. Transformation of monetite to hydroxyapatite in bioactive coatings on titanium. Surf Coat Technol 2001; 137: 270-276.

16. Han Y, Fu T, Xu KW. Characterization and stability of 
hydroxyapatite coatings prepared by an electrodeposition and alkaline-treatment process. J Biomed Mater Res 2001; 54: 96-101.

17. Muzzarelli RA, Biagini G, Bellardini M, Simonelli L, Costaldini C, Fratto G. Osteoconduction exerted by methylpyrrolidinone chitosan used in dental surgery. Biomaterials 1993; 14: 39-43.

18. Muzzarelli RA, Mattioli-Belmonti M, Tiez C, Biagini G, Ferioli G, Brunelli MA. Stimulatory effect on bone formation exerted by a modified chitosan. Biomaterials 1994; 15: 1075-1081.

19. Muzzarelli RA, Zucchini C. Ilari P, Pugnaloni A, Mattioli-Belmonti M, Biagini G. Osteoconductive properties of methylpyrrolidinone chitosan in an animal model. Biomaterials 1993; 14: 925-929.

20. Malette WG, Quigley HJ, Adickes ED. Chitosan effect in vascular surgery, tissue culture and tissue regeneration. In: Muzzarelli R, Jeuniaux C, Gooday GW, editors. Chitin in nature and technology. New York: Plenum Press; 1986. p 435-442.

21. Fradet G, Brister S, Mulder DS, Lough J, Averbach BL. Evaluation of chitosan as a new hemostatic agent: In vitro and in vivo experiments. In: Muzzarelli R, Jeuniaux C, Gooday GW, editors. Chitin in nature and technology. New York: Plenum Press; 1986. p 443451.

22. Minami S, Okamoto T, Matsuhashi A, Sashiwa H, Saimoto H, Shigemasa Y, Tanigawa T, Tanaka Y, Tokura S. Application of chitin and chitosan in large animal practice. In: Brine CJ, Sandford PA, Zikakis JP, editors. Advances in chitin and chitosan. New York: Elsevier Applied Science; 1992. p 61-69.

23. Borah G, Scott G, Wortham K. Bone induction by chitosan in endochondral bones of the extremities. In: Brine CJ, Sandford PA, Zikakis JP, editors. Advances in chitin and chitosan. New York: Elsevier Applied Science; 1992. p 47-53.

24. Muzzarelli R, Baldassarre V, Conti F, Ferrara P, Biagini $\mathrm{G}$, Gazzanelli G. Biological activity of chitosan: Ultrastructural study. Biomaterials 1988; 9: 246-252.

25. Lim L-Y, Khor E, Ling C-E. Effects of dry heat and saturated steam on the physical properties of chitosan. J Biomed Mater Res, Appl Biomater 1999; 48: 111116.

26. Kam H-M, Khor E, Lim L-Y. Storage of partially deacetylated chitosan films. J Biomed Mater Res, Appl Biomater 1999; 48: 881-888.

27. Chellat F, Tabrizian M, Dumitriu S, Chornet E, Rivard C-H, Yahia L'H. Study of biodegradation behavior of chitosan-xanthan microspheres in simulated physiological media. J Biomed Mater Res, Appl Biomater 2000; 53: 592-599.

28. Yamaguchi I, Tokuchi K, Fukuzaki H, Koyama Y, Takakuda K, Monma H, Tananka J. Preparation and microstructure of chitosan/hydroxyapatite nanocomposites. J Biomed Mater Res 2001; 55: 20-27.

29. Elmore KL, Farr TD. Equilibrium in the system calcium oxide-phosphorous pentoxide-water. Ind Eng Chem 1940; 32: 580-586. 